\title{
Covalent biofunctionalization of chitosan nanofibers with trypsin for high enzyme stability
}

\author{
Jana Srbová a , Marcela Slováková a,*, Zuzana Kř̌ipalováa , Monika Žárskáa , Martina Špačková b, \\ Denisa Stránská ${ }^{b}$, Zuzana Bílkováa \\ a Department of Biological and Biochemical Sciences, Faculty of Chemical Technology, University of Pardubice, Studentska 573,53210 Pardubice, Czech Republic \\ b Elmarco Ltd Co, Svarovska 621, 46010 Liberec, Czech Republic
}

\section{A R T I C L E I N F O}

\section{Article history:}

Received 5 November 2015

Received in revised form 4 May 2016

Accepted 10 May 2016

Available online 12 May 2016

\section{Keywords:}

Trypsin

Chitosan

Electrospun nanofibers

Reusability

Biofunctionalization

\begin{abstract}
A B S T R A C T
The electrospun chitosan nanofibers provide excellent material for immobilized proteolytic enzymes, and are biocompatible, nontoxic and hydrophilic matrices with large specific area. This paper deals with an application of electrospun chitosan nanofibers and optimizing conditions for their biofunctionalization by model proteolytic enzyme trypsin. Nanofibers from chitosan were prepared using Nanospider ${ }^{\mathrm{TM}}$ technology and covalent immobilization of trypsin followed. Three immobilization techniques preserving biocompatibility and utilizing amine and/or hydroxyl groups of chitosan were optimized and compared to simple adsorption to achieve maximum proteolytic activity per $\mathrm{cm}^{2}$ of the functionalized chitosan nanofibers (Tryp-NF). Significant differences were observed. Trypsin immobilized by the carbodiimide one-step protocol demonstrated the highest activity of the three procedures, ranging from 132 to $210 \mathrm{IU} / \mathrm{cm}^{2}$ (i.e., 548-874 IU/mg of nanofibers), depending on the initial amount of trypsin used. Long-term storage stability together with high reusability of Tryp-NF confirmed advantages of the immobilized enzyme. Tryp-NF showed no cytotoxicity toward growth of HeLa cells. The in vivo tests for irritation and skin sensitization demonstrated no undesirable skin reactions.
\end{abstract}

(C) 2016 Elsevier B.V. All rights reserved.

\section{Introduction}

Recently, together with the expanding area of nanotechnologies, increasing interest has been reported in biofunctionalization of such various nanostructures as carbon nanotubes, metallic nanoparticles or nanocomposites [1]. The utilization of nanofibers as a support for enzymes immobilization was first reported by Jia et al. in 2002 [2]. Thus immobilized, the enzymes offer such benefits vis-à-vis their use in soluble forms as controllability of the reaction, reusability, and often both enhanced stability and activity [3-6]. Electrospun nanofibers have been proven to provide excellent support for enzyme immobilization [7] because of their high specific surface area-to-volume ratios, mass transfer resistance, and effective loading [8,9]. Moreover, because they can be manufactured in various formats and from different synthetic and natural polymers, they afford great flexibility in surface functionality [9]. In 2006, the new technology for a needle-free, high-voltage electrospinning process known as Nanospider was introduced $[10,11]$. It enabled the production of nanofibers on an industrial scale. Nanofibers prepared using this advanced technique are excellent for their high fiber-diameter uniformity and layer homogeneity. A joining of

\footnotetext{
* Corresponding author.

E-mail address: marcela.slovakova@upce.cz (M. Slováková).
}

these properties with the potential for large-scale fabrication makes these nanofibers even more attractive from a commercial point of view.

Further, biofunctionalized nanofibers (i.e. modified with biological ligands such as enzymes, growth factors, antibiotics etc.) have found interesting applications in different environmental $[12,13]$ or scientific areas [14-16], but their significant characteristics and superiority was demonstrated especially in the expanding area of biomedicine. They can serve as scaffolds or vehicles in drug delivery systems [17], tissue engineering [18] or wound healing [19]. We have focused on the chitosan nanofibers and their biofunctionalization with enzymes for the purpose of wound healing. Chitosan is a derivative of chitin and is a natural polyaminosaccharide offering a set of unique characteristics that include (among others) biocompatibility, biodegradability, nontoxicity, antibacterial properties, and hydrophilicity [20]. The nanofibrous form of chitosan brings additional attractive features like large surface area and porosity leading to good permeability for oxygen and water [21, 22 ]. These properties support cell respiration, skin regeneration, moisture retention, removal of exudates, and hemostasis [23].

The idea of using proteolytic enzymes during the treatment of wounds is rather old [24-27] and relies on enzymatic debridement of necrotic tissue in wounds and support of cell migration. It can be used alone or in combination with other techniques, such as negative pressure therapy [28] or surgical debridement [27]. Typical debriding agents are collagenase and papain in combination with urea; they are 
commercially available in the form of ointments [29]. Here, trypsin, serine protease cleaving the peptides on the C-terminal side of lysine and arginine amino acid residues, was selected as a model proteolytic enzyme with a well-understood mode of action and undemanding colorimetric measurement of its activity. The benefits of using immobilized proteolytic enzymes for wound healing are the possibility to control the cleavage of necrotic tissue and also the prolonged enzymatic activity compared to the soluble form of enzyme.

The goal of this work was to optimize the preparation of enzymatically highly active and stable nanofibers which have the potential to be used as a bioactive wound dressing. Electrospun nanofibers from chitosan were prepared using the needleless Nanospider technology and applied as support for immobilization of trypsin. Even though chitosan nanofibers have tremendous potential for applications in biomedicine [21], techniques for their biofunctionalization with proteolytic enzymes have been poorly explored to date. In this study, three different immobilization strategies, carbodiimide one-step and two-step coupling through the terminal amine and hydroxyl moieties and periodate oxidation targeting hydroxyl groups of chitosan, were applied. All techniques were optimized from the perspective of enzyme yields. The reusability and storage stability of enzyme-functionalized nanofibers were investigated. Then, both in vitro and in vivo cytotoxicity testing of the trypsinfunctionalized nanofibers followed.

\section{Materials and methods}

\subsection{Chemicals}

Trypsin from bovine pancreas (EC 3.4.21.4; 13,335 IU/mg), sodium cyanoborohydride, sodium (meta) periodate, benzamidine hydrochloride hydrate, $N$-(3-dimethylaminopropyl)- $N$ '-ethylcarbodiimide hydrochloride (EDC), $N$-hydroxysulfosuccinimide sodium salt (sulfoNHS), $N$ - $\alpha$-benzoyl-DL-arginine 4-nitroanilide hydrochloride (BApNA), tris (hydroxymethyl) aminomethane, 4-(2-hydroxyethyl) piperazine1-ethanesulfonic acid (HEPES), and 2-( $N$-morpholino) ethanesulfonic acid (MES) were purchased from Sigma Aldrich (St. Louis, MO, USA). Chitosan (food grade, without molecular mass specification) was purchased from AK Biotech (deacetylation degree 91.1\%; Qianlong, China) and polyethylene oxide (PEO) with a molecular weight of 400 kDa from Scientific Polymer Products (New York, NY, USA). Other chemicals were of analytical grade and obtained from Penta (Chrudim, Czech Republic) or Lach-Ner (Neratovice, Czech Republic). All buffers and solutions were prepared from ultrapure water filtered through a TKA Smart2Pure system (Thermo Scientific TKA, Niederelbert, Germany).

\subsection{Manufacturing of chitosan nanofibers}

A solution of chitosan in $66 \%$ acetic acid ( $6 \mathrm{wt} \%$ ) was stirred at $50{ }^{\circ} \mathrm{C}$ until a homogeneous polymer solution was obtained. An aqueous solution of 3\% PEO was subsequently added to the cooled chitosan solution. The nanofibers were prepared using the modified needleless Nanospider ${ }^{\mathrm{TM}}$ technology [30] on an NS LAB 500S electrospinning laboratory device from Elmarco Ltd. (Liberec, Czech Republic). The conditions during the electrospinning process were as follow: the spinning electrode was cylindrical (rotation speed $4 \mathrm{rpm}$ ), electrode distance was $130 \mathrm{~mm}$, and voltage was $60 \mathrm{kV}$. Polypropylene spunbond (17 g/m²; Pegas Nonwovens, Znojmo, Czech Republic) was used as the substrate, and the speed depended on the required basis weight. The crosslinking of nanofibers was achieved post-synthetically by heat treatment $\left(130{ }^{\circ} \mathrm{C}, 1 \mathrm{~h}\right)$. Chitosan nanofibers were cut into squares $(1.5 \times 1.5 \mathrm{~cm})$. Prior to biofunctionalization of the nanofibers, polypropylene spunbonds were then torn off and all squares were weighted.

\subsection{Scanning electron microscopy}

A VEGA3 TESCAN scanning electron microscope (SEM) with detector of primary electrons was used to observe the nanofibers' structure and evaluate their diameters. In order to increase its conductivity, the sample was coated with an Au layer $(0.2 \mathrm{~nm})$ using Balzers dust sprinkling equipment. Fiber diameters were determined as mean values of 35 measurements on the SEM images at 5000× magnification.

\subsection{Immobilization of trypsin}

The enzyme trypsin was immobilized on the $1.5 \times 1.5 \mathrm{~cm}$ chitosan squares according to the protocols described in Sections 2.4.1 and 2.4.2. All measurements were repeated a minimum of three times, the calculated means and SD values of which are shown in the graphs herein.

\subsubsection{Sodium periodate oxidation of chitosan and trypsin immobilization}

Nanofibrous squares were placed in $2.0 \mathrm{~mL}$ polypropylene tubes and rehydrated using $0.5 \mathrm{~mL}$ of $0.01 \mathrm{M}$ phosphate buffer ( $\mathrm{pH}$ 7.3). A solution of sodium periodate was added (volume of $0.5 \mathrm{~mL} ; 0.05 \mathrm{M}$ periodate in $0.025 \mathrm{M}$ HEPES pH 7.3). This was followed by oxidation in darkness under rotation $(1.5 \mathrm{~h}$ ) and five washing steps with $0.01 \mathrm{M}$ phosphate buffer ( $\mathrm{pH}$ 7.3). A trypsin solution with benzamidine in the volume of $0.9 \mathrm{~mL}$ was added to the activated nanofibers (unless stated otherwise, $3 \mathrm{mg}$ of trypsin with $0.3 \mathrm{mg}$ of benzamidine dissolved in the $0.01 \mathrm{M}$ phosphate buffer [pH 7.3]). After $10 \mathrm{~min}$ of incubation (RT, rotation), $3 \mathrm{mg}$ of sodium cyanoborohydride in $0.1 \mathrm{~mL}$ of the $0.1 \mathrm{M}$ phosphate buffer ( $\mathrm{pH} 7.3$ ) was pipetted to the nanofibers to stabilize the labile Schiff base. Immobilization was carried out at $4{ }^{\circ} \mathrm{C}$ and rotation for $16 \mathrm{~h}$. The Tryp-NF were washed three times using $1 \mathrm{~mL}$ of $0.1 \mathrm{M}$ phosphate buffer ( $\mathrm{pH} 7.3$ ), once with $1 \mathrm{~mL}$ of the same buffer containing $1 \mathrm{M} \mathrm{NaCl}$, and twice with $1 \mathrm{~mL}$ of $0.1 \mathrm{M}$ phosphate buffer ( $\mathrm{pH} 7.3$ ).

\subsubsection{Carbodiimide method of trypsin immobilization}

2.4.2.1. One-step carbodiimide method. Nanofibrous squares were rehydrated by $1 \mathrm{~mL}$ of $0.01 \mathrm{M}$ phosphate buffer ( $\mathrm{pH}$ 7.3). The supernatant was removed and the zero-length crosslinker EDC $(7.5 \mathrm{mg})$ and sulfo-NHS (1.25 mg) reagent (each dissolved in $0.25 \mathrm{~mL}$ of $0.01 \mathrm{M}$ phosphate buffer ( $\mathrm{pH} 7.3)$ ) were quickly added to the nanofibers. Immediate addition of trypsin solution with benzamidine followed (unless stated otherwise, $3 \mathrm{mg}$ of trypsin with $0.3 \mathrm{mg}$ of benzamidine dissolved in $0.5 \mathrm{~mL}$ of $0.01 \mathrm{M}$ phosphate buffer [pH 7.3]). The immobilization proceeded at $4{ }^{\circ} \mathrm{C}$ for $16 \mathrm{~h}$ under rotation. Subsequent washing was carried out identically as in the periodate method. For the in vitro and in vivo experiments Tryp-NF squares with dimensions of $9 \times 9 \mathrm{~cm}$ were prepared with slight modifications. Briefly, the nanofibers were cut and rehydrated in $15 \mathrm{~mL}$ of $0.01 \mathrm{M}$ phosphate buffer ( $\mathrm{pH} 7.3$ ). The addition of EDC ( $56 \mathrm{mg}$ ), sulfo-NHS ( $9.4 \mathrm{mg}$ ) and trypsin with benzamidine (10 mg of trypsin, $1 \mathrm{mg}$ of benzamidine) followed; the immobilization was performed in the total volume of $15 \mathrm{~mL}$. The Tryp-NF were washed three times using $15 \mathrm{~mL}$ of $0.1 \mathrm{M}$ phosphate buffer ( $\mathrm{pH} 7.3$ ), once with $15 \mathrm{~mL}$ of the same buffer containing $1 \mathrm{M} \mathrm{NaCl}$, and twice with $15 \mathrm{~mL}$ of $0.1 \mathrm{M}$ phosphate buffer ( $\mathrm{pH} 7.3$ ).

2.4.2.2. Two-step carbodiimide method. The procedure was similar to the one-step procedure with the following distinction. The EDC and sulfoNHS were dissolved in the volume of $0.5 \mathrm{~mL}$ and were added to the washed nanofibers. The activation process continued for $120 \mathrm{~min}$ and the supernatant was then replaced by $1 \mathrm{~mL}$ of trypsin solution with benzamidine (unless stated otherwise, $3 \mathrm{mg}$ of trypsin with $0.3 \mathrm{mg}$ of benzamidine dissolved in $1 \mathrm{~mL}$ of the $0.01 \mathrm{M}$ phosphate buffer [ $\mathrm{pH} 7.3]$ ). 


\subsubsection{Adsorption of trypsin}

Nanofibrous squares were placed in $2.0 \mathrm{~mL}$ polypropylene tubes and rehydrated using $1 \mathrm{~mL}$ of $0.01 \mathrm{M}$ phosphate buffer ( $\mathrm{pH} 7.3$ ). The procedure was similar to the one-step procedure with the following distinction. The supernatant was removed and $0.5 \mathrm{~mL}$ of $0.01 \mathrm{M}$ phosphate buffer ( $\mathrm{pH} 7.3$ ) and trypsin solution with benzamidine (unless stated otherwise, $3 \mathrm{mg}$ of trypsin with $0.3 \mathrm{mg}$ of benzamidine dissolved in $0.5 \mathrm{~mL}$ of $0.01 \mathrm{M}$ phosphate buffer [pH 7.3]) were added to the nanofibers. The immobilization proceeded at $4{ }^{\circ} \mathrm{C}$ for $16 \mathrm{~h}$ under rotation. Subsequent washing was carried out identically as in the periodate method.

\subsection{Storage and desiccation of Tryp-NF}

Tryp-NF were stored in $1 \mathrm{~mL}$ of $0.1 \mathrm{M}$ phosphate buffer ( $\mathrm{pH} 7.3$ ) with sodium azide $(0.1 \% \mathrm{w} / \mathrm{v})$ and benzamidine $(0.03 \mathrm{w} / \mathrm{v})$ at $4{ }^{\circ} \mathrm{C}$. Desiccation ( $24 \mathrm{~h}$ ) and storage of desiccated nanofibers occurred in the air at laboratory temperature. Prior to determining trypsin activity, Tryp-NF were rehydrated for $10 \mathrm{~min}$ in $2 \mathrm{~mL}$ of ultrapure water and then washed with ultrapure water $(3 \times 1 \mathrm{~mL})$ and finally with $0.05 \mathrm{M}$ Tris-HCl buffer, pH $7.8(1 \times 1 \mathrm{~mL})$.

\subsection{Determination of trypsin activity}

Soluble and immobilized trypsin activity was determined using the low-molecular-weight chromogenic substrate BApNA according to a method from the literature [31] in the final reaction volume of $2 \mathrm{~mL}$. Using a MultiScan RC spectrophotometric reader (Labsystems, Helsinki, Finland), absorbance at $405 \mathrm{~nm}$ was measured and trypsin activity per $\mathrm{cm}^{2}$ was calculated. The activity of the immobilized enzyme was determined in terms of active units (U), with one unit of enzymatic activity being defined as the quantity of enzyme catalyzing the production of $1 \mu \mathrm{mol}$ of pNA per min. The following formula can be used for recalculating the trypsin activity to $\mathrm{IU} / \mathrm{mg}$ : (enzyme activity per $\mathrm{cm}^{2}$ ) / (weight of $2.25 \mathrm{~cm}^{2}$ of nanofibers of the particular basis weight [i.e., $0.54 \mathrm{mg}$ for $2.4 \mathrm{~g} / \mathrm{m}^{2}$ and 0.63 for $2.8 \mathrm{~g} / \mathrm{m}^{2}$ nanofibers]).

\subsection{Tests for in vitro cytotoxicity}

For these experiments squares of Tryp-NF were prepared according to the method described in Section 2.4.2 - the one-step method. The cytotoxicity of prepared Tryp-NF was examined in the Certified Laboratory of Tissue Cultures in Nove Hrady, Czech Republic, according to the CSN EN ISO 10993-5, Biological evaluation of medical devices - tests for in vitro cytotoxicity (8.2 and 8.3). All experiments were performed with HeLa cells (ECACC 09E047).

\subsection{Tests for in vivo irritation and skin sensitization}

For these experiments squares of Tryp-NF were prepared according to the method described in Section 2.4.2 - the one-step method. The intracutaneous (intradermal) reactivity test after the application of Tryp$\mathrm{NF}$ to the albino rabbits was carried out in the Certified Laboratory Nr. 1057 of VUOS, Rybitvi, Czech Republic according to the CSN EN ISO 10993-10, Biological evaluation of medical devices - tests for irritation and skin sensitization (6.4).

\section{Results and discussion}

\subsection{Preparation of chitosan nanofibers}

In this study a robust strategy for covalent biofunctionalization of chitosan nanofibers with proteolytic enzymes without altering their mechanical integrity is presented. The work was carried out with the aim to prepare proteolytic highly active and stable nanofibers with potential of advanced bioactive wound dressing. Due to proposed application, the following particularities were defined for this study: (i) the enzyme activity per unit area $\left(\mathrm{cm}^{2}\right)$ was more relevant than was the usual activity per mass expression (see Section 2.6 for recalculating activity per unit area to mass); (ii) nanofibers from the biocompatible polymer chitosan and heat-mediated post-synthetic crosslinking of nanofibers without any additional chemicals were chosen; (iii) glutaraldehyde, an often used homobifunctional crosslinking agent for enzyme immobilization, was deliberately omitted from the procedure to assure the highest possible biocompatibility and minimal irritant effects when coming into contact with tissues.

For preparation of the nanofibers, we used the modified needleless Nanospider ${ }^{\mathrm{TM}}$ technology [30], in which polymeric jets are spontaneously formed from liquid surfaces on a rotating spinning electrode. Generally, this technology enables flexibly the formation of fibers tens of nanometers to tens of micrometers in diameter and the preparation of nanofibers with masses per unit area ranging from 1 to $100 \mathrm{~g} / \mathrm{m}^{2}$. The thinner the nanofibers are the more functional groups they carry for conjugation reactions with the enzymes which results in increased enzyme loading, as reported several times [2,32]. Here we aimed at chitosan matrices with fibers diameter between 100 and $150 \mathrm{~nm}$ and low basis weight (i.e., fiber weight per area) supporting the oxygen permeability and thus the breathability of the nanofibrous layer. Therefore chitosan nanofibers of basis weight from 1 to $2.8 \mathrm{~g} / \mathrm{m}^{2}$ were prepared and characterized, as summarized in Table 1 . The diameter of prepared fibers ranged from 107.7 up to $165.1 \mathrm{~nm}$. The homogeneity and uniformity of the prepared chitosan nanofibers was evaluated using SEM (Fig. 1A-C). Nanofiber squares with a high degree of homogeneity and no structural defects were chosen for the experiments. Unless specified otherwise in the text, nanofibers of 2.4 or $2.8 \mathrm{~g} / \mathrm{m}^{2}$ were used for the functionalization.

\subsection{Covalent biofunctionalization of chitosan nanofibers with trypsin}

As has been described in numerous reviews, the methods applied for enzyme immobilization on nanofibers do not differ from standard bioconjugation techniques [33] and include adsorption, covalent immobilization, enzyme entrapment and encapsulation [5,34,35]. From this list, covalent bonding is often preferred because it provides stable linkage between enzymes and nanofibers. Glutaraldehyde crosslinking [32, $36]$ and carbodiimide chemistry $[37,38]$ are two covalent techniques most commonly applied for biofunctionalization of nanofibers and typically result in high loading yields. Here, two different immobilization approaches (oxidation of carbohydrates on chitosan and carbodiimide coupling) were used with various modifications, optimized, and finally compared from the viewpoint of the immobilized trypsin's activity achieved (Fig. 2).

Even though chitosan belongs among polysaccharides with great potential for medicinal applications and is insoluble in water, the presence of amine groups makes it soluble in acidic solutions with $\mathrm{pH}$ below 6.5 [20]. Careful choice of the reaction environment (such as $\mathrm{pH}$ ) during all steps of trypsin conjugation is thus a key condition for preserving nanofibers integrity and thus the development of stable nanofibrous layers with high proteolytic activity and was also investigated in this study.

Table 1

Characteristics of prepared chitosan nanofibers.

\begin{tabular}{lll}
\hline Polymer & Basis weight $\left[\mathrm{g} / \mathrm{m}^{2}\right]$ & Fiber diameter $\pm \mathrm{SD}[\mathrm{nm}]$ \\
\hline & 1.0 & $148.4 \pm 46.7$ \\
& 1.2 & $126.1 \pm 19.4$ \\
Chitosan & 1.4 & $135.8 \pm 28.3$ \\
& 1.7 & $165.1 \pm 45.8$ \\
& 2.2 & $137.5 \pm 25.5$ \\
& 2.5 & $128.9 \pm 18.9$ \\
& 2.4 & $107.7 \pm 18.8$ \\
\hline
\end{tabular}


A

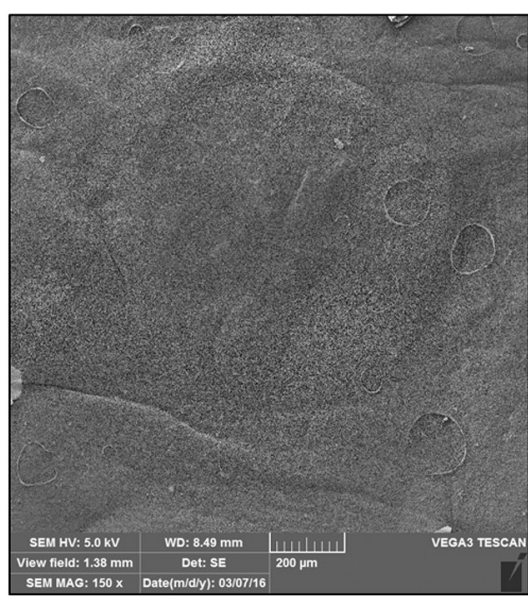

B

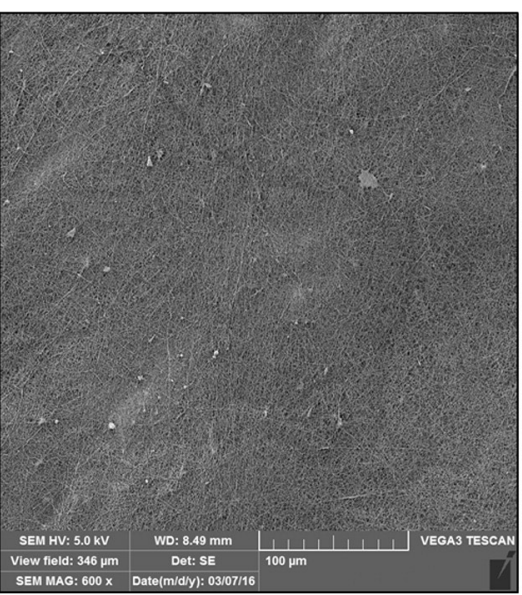

C

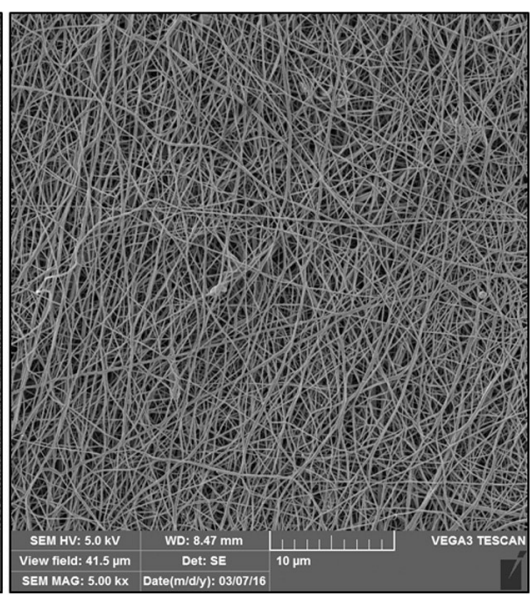

Fig. 1. Scanning electron microscope images of prepared chitosan nanofibers (basis weight $2.8 \mathrm{~g}$ per $\left.\mathrm{m}^{2}\right)$. Magnification: $(\mathrm{A}) 150 \times,(B) 600 \times,(\mathrm{C}) 5,000 \times$.

\subsection{Trypsin conjugation to periodate-activated carbohydrates of chitosan nanofibers}

The first immobilization method applied in this study is based upon mild oxidation of carbohydrates on chitosan using sodium periodate, which acts on the adjacent hydroxyl groups. Highly reactive aldehyde groups are thereby created and react with an amine-containing ligand, in our case trypsin. Reductive amination follows to form a highly stable covalent linkage and a zero-length crosslink [39].

Nanofibers oxidation was performed in distilled water, $0.1 \mathrm{M}$ borate buffer ( $\mathrm{pH} 10$ ), $0.1 \mathrm{M}$ carbonate buffer ( $\mathrm{pH} 9.0$ ), $0.01 \mathrm{M}$ phosphate buffer ( $\mathrm{pH} 7.3$ ), $0.025 \mathrm{M}$ HEPES ( $\mathrm{pH} 7.3$ ) or their mixtures. The only option leading to unmodified appearance of nanofibers after the oxidation step (evaluated using SEM) consisted in the dissolution of the sodium periodate in 0.025 M HEPES ( $\mathrm{pH} 7.3$ ) and the addition of nanofibers that had previously been hydrated in $0.01 \mathrm{M}$ phosphate buffer ( $\mathrm{pH} 7.3$ ).

The effect of increasing the amount of trypsin (1, 2, 3, 4 and $5 \mathrm{mg}$ ) used for the biofunctionalization of periodate-activated nanofibers on the final activity of immobilized trypsin was then investigated (see Fig. 3). The maximum achieved enzyme activity was $57.58 \mathrm{IU} / \mathrm{cm}^{2}$ and was attained after the immobilization of $4 \mathrm{mg}$ of trypsin. The immobilization of higher quantities of trypsin $(>4 \mathrm{mg}$ ) did not lead to higher enzyme activity and was thus redundant. In parallel with the covalent attachment of trypsin to nanofibers the effect of increasing the amount of trypsin adsorbed to the nanofiber squares was studied. Activity measurements after adsorption confirmed that adsorbed trypsin nanofiber achieved incomparably low $\mathrm{IU} / \mathrm{cm}^{2}$, only $3.48 \%$ of activity achieved by the periodate method corresponding to $4 \mathrm{mg}$ of trypsin (Fig. 3). Simple adsorption of trypsin molecules to nanofibers structure followed by washing steps could not ensure stable bond.

\subsection{Trypsin conjugation to chitosan nanofibers by carbodiimide method}

The second immobilization approach relies on the formation of amide and ester linkages mediated by the zero-length crosslinker carbodiimide (EDC). The addition of sulfo-NHS to the EDC-mediated reaction increases the solubility and stability of the active intermediate $O$ acylisourea subsequently reacting with the amine and hydroxyl group of chitosan [40]. EDC/sulfo-NHS-coupled reactions are generally considered as highly efficient [39] and can be performed using a one- or twostep procedure. Here both variants were examined.

The suitable $\mathrm{pH}$ for immobilization of trypsin using the one-step carbodiimide technique was investigated with the aim of achieving maximum activity of immobilized trypsin while maintaining the integrity of chitosan nanofibers. No pronounced influence of $\mathrm{pH}$ of phosphate buffer on trypsin coupling was observed (Fig. 4). Although the highest trypsin activity was measured after immobilization at $\mathrm{pH} 6.5$ (190.36 IU of trypsin per $\mathrm{cm}^{2}$ of nanofibers), the structure of nanofibers was in that case slightly disintegrated (data not shown). Phosphate buffer at pH 7.3 was selected as a coupling buffer for the subsequent experiments ( $167.7 \mathrm{IU}$ of trypsin per $\mathrm{cm}^{2}$ ), and this provided a good environment to maintain the structural integrity of nanofibers.

In the case of the two-step carbodiimide immobilization method, the extra optimization time required for the activation of nanofibers with EDC and sulfo-NHS reagents was vital. Different activation times in the interval from 15 to 120 min were tested in order to achieve maximum

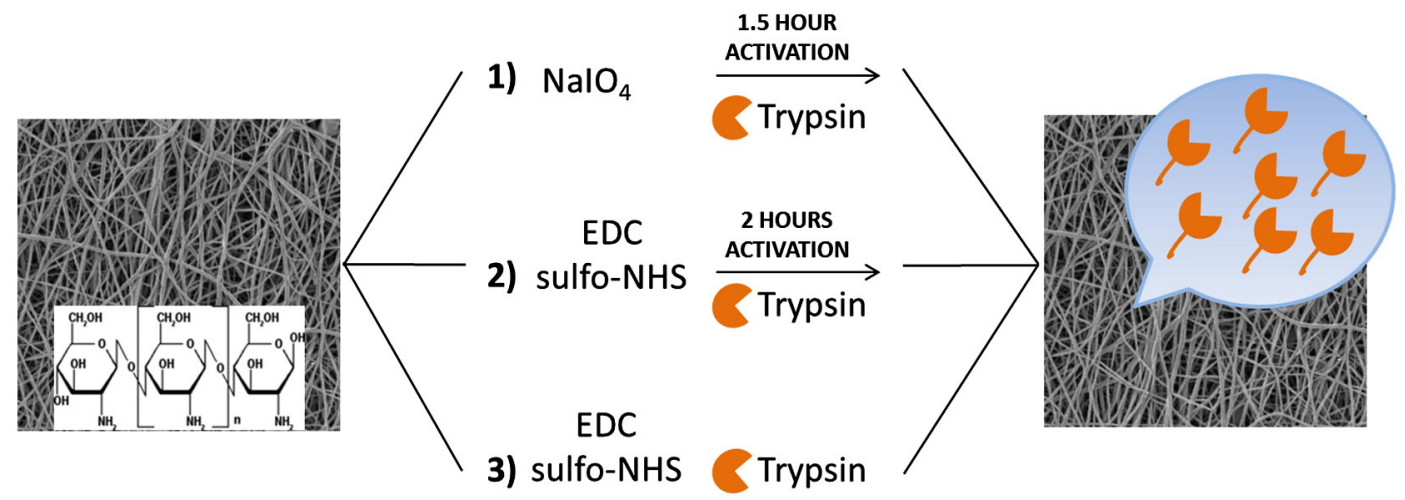

Fig. 2. Overview of coupling strategies to immobilize trypsin to the chitosan nanofibers. 


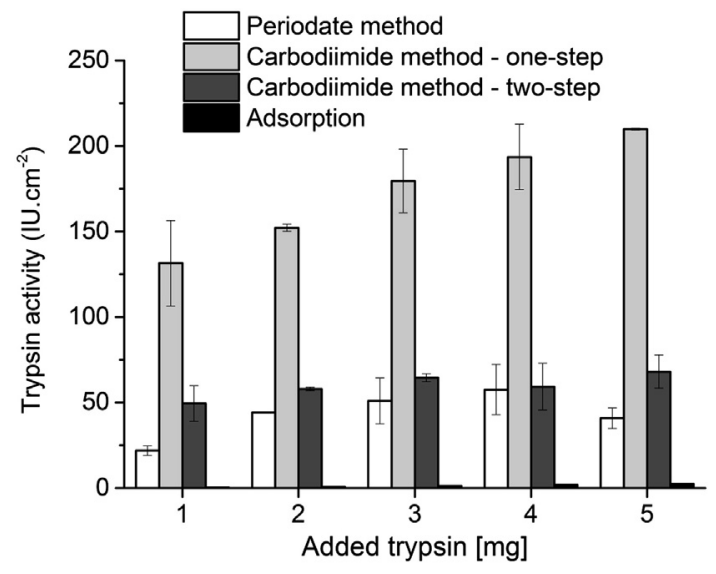

Fig. 3. Optimization of the amount of trypsin to be immobilized on chitosan nanofibers $(1.5 \times 1.5 \mathrm{~cm})$ by the trypsin conjugation to periodate-activated nanofibers, by the carbodiimide methods (one- and two-step method) and by the trypsin adsorption.

proteolytic activity of the prepared nanofibers. An increasing trend was observed; the highest trypsin activity was achieved after the longest activation time (i.e., $120 \mathrm{~min}$; Fig. 5). Further prolongation of the activation time has not been tested since it would lead to the unwanted extension of biofunctionalization time of Tryp-NF. Even after this improvement in the method, however, enzyme yields did not exceed the trypsin activity achieved after trypsin immobilization using the previously described one-step carbodiimide method.

To find the optimal amount of trypsin for the biofunctionalization of chitosan nanofibers using both variants of the carbodiimide protocols, increasing quantities of trypsin were added to the immobilization mixture (1, 2, 3, 4, and $5 \mathrm{mg}$ of trypsin, see Fig. 3). Significant differences were observed between the one-step and two-step variants in the final activities of immobilized trypsin. With the increasing amounts of trypsin added into the reaction, the activity of trypsin-functionalized nanofibers using the one-step protocol increased almost linearly. Trypsin immobilization using the one-step carbodiimide method was proven as the best approach resulting in the activity from $131.51 \mathrm{IU} / \mathrm{cm}^{2}$ up to $209.80 \mathrm{IU} / \mathrm{cm}^{2}$ and was applied for preparation of Tryp-NF for the stability experiments and also for preliminary toxicity testing. The reported trypsin loading (expressed as IU/mg) was comparable or even higher than in the literature describing the immobilization of alpha-chymotrypsin on silk fibroin nanofibers [36] or lipase to poly(acrylonitrileco-maleic acid) [32].

The effect of different basis weights of chitosan nanofibers on trypsin loading was investigated. Hypothetically, with the increasing basis weight of nanofibers of the same dimensions (e.g. in our case $1.5 \times 1.5 \mathrm{~cm}$ ) the increasing amount of functional groups should be exposed for enzyme coupling which could lead to higher enzyme loading.

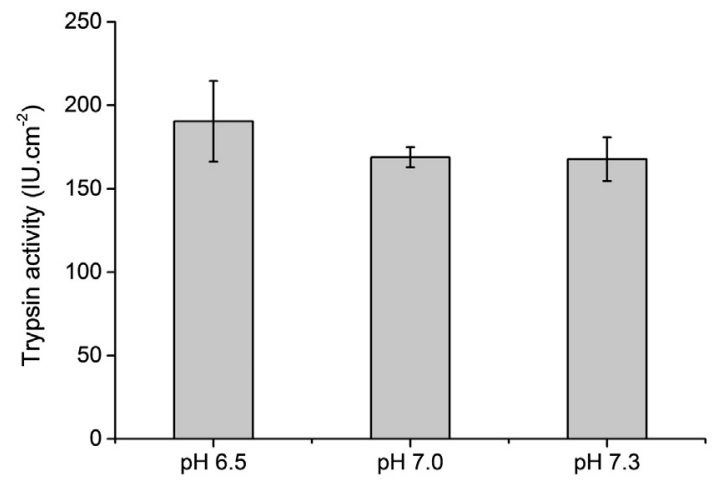

Fig. 4. Effect of $\mathrm{pH}$ of immobilization buffer on activity of immobilized trypsin (carbodiimide one-step method).

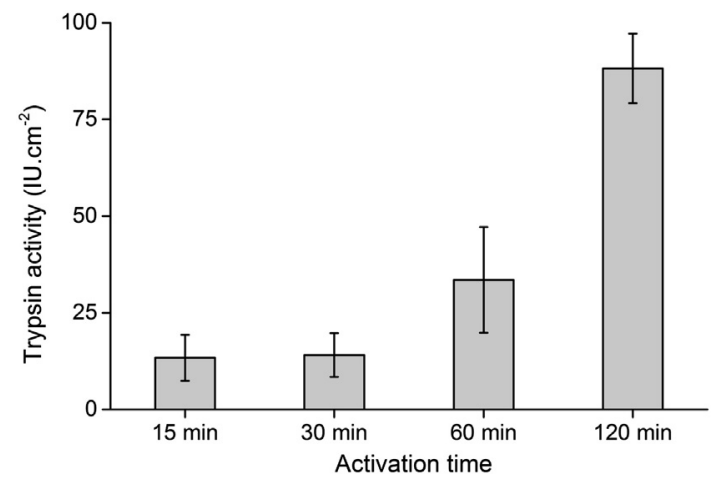

Fig. 5. Effect of activation time (i.e., activation of nanofibers with EDC plus sulfo-NHS reagents) on activity of trypsin immobilized by the two-step carbodiimide method on chitosan nanofibers.

Therefore electrospun chitosan nanofibers of approx. same diameter (Table 1) but different weights were prepared and biofunctionalized using the one-step carbodiimide method as you can see in Fig. 6. Our hypothesis has not been confirmed; there was no unambiguous dependence between the density of nanofibers and the amount of active trypsin immobilized on them. This could be caused by the restricted accessibility of trypsin to the inner layers of thicker nanofibrous matrices, especially after their hydration and swelling in aqueous buffers.

\subsection{Storage stability and reusability of trypsin-functionalized nanofibers}

Storage stability as well as reusability belongs among generally important parameters for enzyme carriers applied in the field of biocatalysis. It also testifies about the quality of the binding of the enzyme to the carrier. Covalent enzyme immobilization typically improves the stability of enzymes [5], as has been reported several times already when nanofibers have been used as support [41]. These parameters are particularly important in case of enzymes with the ability of autolysis, as trypsin. Here, the storage stability of Tryp-NF was monitored for 4 weeks in both desiccated and hydrated form (Fig. 7). Higher enzyme activity was achieved when the biofunctionalized nanofibers were desiccated and stored in a dried state, which indicated their preliminary suitability as wound dressings since the dry material form is practical and also strongly demanded by the potential end users. Dry form of storage also excludes the risk of autolytic self-degradation of trypsin in time. Nevertheless, in both cases trypsin activity after 4 weeks of storage exceeded $90 \%$ compared to the initial activity measured immediately after immobilization. An increase in trypsin activity recorded after 1 week of storage (particularly evident on dry nanofibers) is a commonly observed phenomenon caused by the restoration of functional conformation leading to enzyme reactivation [32]. To compare the

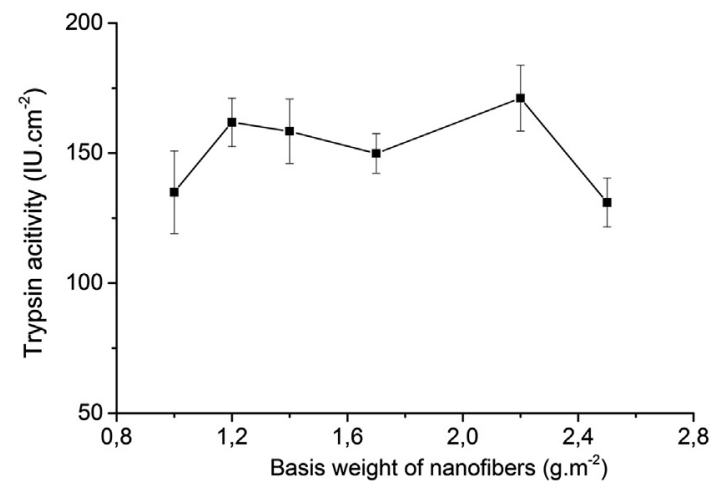

Fig. 6. Effect of different basis weights of chitosan nanofibers on activity of trypsin immobilized by the carbodiimide one-step procedure. 


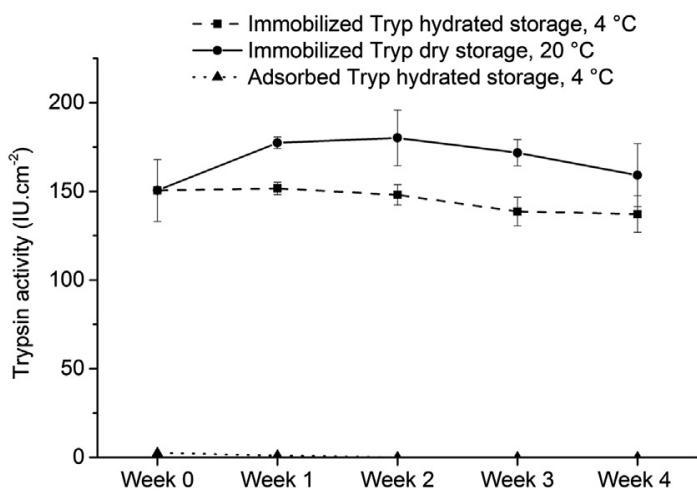

Fig. 7. Effect of storage time and conditions on activity of trypsin immobilized on chitosan nanofibers by the carbodiimide one-step procedure and by the adsorption.

stability of the covalent immobilization method trypsin was in parallel adsorbed to the nanofiber squares. The trypsin activity was monitored during 4 weeks (Fig. 7). Activities of the trypsin adsorbed to nanofibers were very low and decreased to zero $\mathrm{IU} / \mathrm{cm}^{2}$ in 3rd week of the storage. Simultaneously with the experiment the stability of soluble trypsin was observed, which showed a decrease in activity of $42.8 \%$ in 5 days. These experiments repeatedly confirmed high and sufficient proteolytic activity of stored Tryp-NF.

The reusability of trypsin immobilized on nanofibers was determined five times in a row during 1 day and even after the last run the enzyme activity did not fall under $97 \%(98.4 \pm 1.2)$. The reusability of trypsin adsorbed on nanofibers comprised only $0.3 \%$ of the activity immobilized Tryp-NF, and other measurements showed a decrease in activity to zero. These results clearly showed the excellent ability of immobilized Tryp-NF to repeatedly cleave the target substrate without any substantial activity loss. This is extremely beneficial feature from the point of view of the intended application, since it might prolong the duration of the action of this wound dressing without the need of redressing.

3.6. Preliminary in vitro evaluation of cytotoxicity of Tryp-NF and in vivo tests for irritation and skin sensitization

The preliminary toxicity tests with Tryp-NF were done according to standardized ISO procedures in the certified laboratories with the appropriate facilities. The in vitro tests were designed to determine the biological response of mammalian cells (HeLa cells) exposed directly to Tryp-NF and to extracts of Tryp-NF in the Eagle's Minimum Essential Medium. No signs of cytotoxicity toward HeLa cells were found after the direct contact with neither nanofibers nor the infusion from Tryp$\mathrm{NF}$. For the in vivo experiments for intracutaneous (intradermal) reactivity, the Tryp-NF were extracted to sterile water (as a polar solvent) and olive oil (nonpolar solvent) and both extracts were injected intracutaneously at five sites on one side of each albino rabbit. The appearance of each injection site immediately after injection and at $(24 \pm 2) \mathrm{h}$, $(48 \pm 2) \mathrm{h}$ and $(72 \pm 2) \mathrm{h}$ after injection were observed and possible skin reactions (erythema and/or oedema) were recorded. It was demonstrated that both extracts from Tryp-NF has not caused any cutaneous reaction on albino rabbit and no signs of toxicity were observed. All these results supported the idea of using of nanofibers with immobilized proteolytic enzymes as the bioactive wound dressings.

\section{Conclusions}

In this work, biocompatible chitosan electrospun nanofibers prepared using a needleless electrospinning technology were biofunctionalized with the enzyme trypsin. Not only trypsin activity but also the nanofibers' integrity were important parameters taken into account in optimizing all steps during the nanofibers' biofunctionalization. Maximum trypsin activity and excellent wholeness of chitosan nanofibers were achieved when the onestep EDC + sulfo-NHS method was performed. This resulted in activity up to $209.8 \pm 0.6 \mathrm{IU} / \mathrm{cm}^{2}$ of nanofibers. The two-step EDC + sulfo-NHS protocol yielded activity up to $88.2 \pm 8.9 \mathrm{IU} /$ $\mathrm{cm}^{2}$ and the periodate oxidation method up to $57.6 \pm 14.7 \mathrm{IU} /$ $\mathrm{cm}^{2}$. To compare, the adsorption of trypsin resulted in activity up to $2.49 \mathrm{IU} / \mathrm{cm}^{2}$ of nanofibers. This study confirmed that nanofibers from chitosan can serve as an excellent support for enzyme immobilization, and especially when each step of biofunctionalization is thoroughly optimized in order to prevent dissolution or disintegration of the nanofibrous structure. The excellent stability and reusability of trypsin immobilized on chitosan nanofibers together with no toxicity of Tryp-NF reported here suggests their potential in enzyme debridement for skin regeneration.

\section{Acknowledgement}

The authors wish to acknowledge the Ministry of Industry and Trade of the Czech Republic for financial support of the research program under the project MPO TIP FR-TI1/0436.

\section{References}

[1] C. Kumar, Biofunctionalization of Nanomaterials, first ed. Wiley-VCH, Weinheim, 2005

[2] H. Jia, G. Zhu, B. Vugrinovich, W. Kataphinan, D.H. Reneker, P. Wang, Enzyme-carrying polymeric nanofibers prepared via electrospinning for use as unique biocatalysts, Biotechnol. Prog. 18 (2002) 1027-1032.

[3] A. Liese, L. Hilterhaus, Evaluation of immobilized enzymes for industrial applications, Chem. Soc. Rev. 42 (2013) 6236-6249.

[4] S. Chakraborty, H. Rusli, A. Nath, J. Sikder, C. Bhattacharjee, S. Curcio, E. Drioli, Immobilized biocatalytic process development and potential application in membrane separation: a review, Crit. Rev. Biotechnol. 36 (2016) 43-58.

[5] L. Cao, R.D. Schmid, Carrier-Bound Immobilized Enzymes: Principles, Application and Design, first ed. Wiley-VCH Verlag GmbH \& Co. KGaA, Weinhein, 2006

[6] W. Tischer, F. Wedekind, Immobilized Enzymes: Methods and Applications, in: W. Fessner, A. Archelas, D.C. Demirjian, et al., (Eds.), Biocatalysis - from Discovery to Application, Springer, Berlin Heidelberg 1999, pp. 95-126.

[7] Z. Wang, L. Wan, Z. Liu, X. Huang, Z. Xu, Enzyme immobilization on electrospun polymer nanofibers: an overview, J. Mol. Catal. B 56 (2009) 189-195.

[8] H. Jia, Enzyme-carrying Electrospun Nanofibers, in: P. Wang (Ed.), Nanoscale Biocatalysis, Humana Press 2011, pp. 205-212.

[9] N. Bhardwaj, S.C. Kundu, Electrospinning: a fascinating fiber fabrication technique, Biotechnol. Adv. 28 (2010) 325-347.

[10] S. Petrik, M. Maly, Electrospun Nanofiber - The Tiny Layers that Add Great Value to Nonwovens, Proc. of International Nonwoven Symposium, EDANA, Stockholm, 2008.

[11] O. Jirsak, K. Kalinova, D. Stranska, Nanofibre Technologies and Nanospider Applications, Nanofair 2006 New Ideas for Industry, 1940 2006, pp. 41-44.

[12] S. Lee, L.H. Jin, J.H. Kim, S.O. Han, H.B. Na, T. Hyeon, Y. Koo, J. Kim, J. Lee, Beta-glucosidase coating on polymer nanofibers for improved cellulosic ethanol production, Bioprocess Biosyst. Eng. 33 (2010) 141-147.

[13] D. Han, S. Filocamo, R. Kirby, A.J. Steckl, Deactivating chemical agents using enzymecoated nanofibers formed by electrospinning, ACS Appl. Mater. Interfaces 3 (2011) 4633-4639.

[14] D.M. du Plessis, M. Botes, L.M.T. Dicks, T.E. Cloete, Immobilization of commercial hydrolytic enzymes on poly (acrylonitrile) nanofibers for anti-biofilm activity, J. Chem. Technol. Biotechnol. 88 (2013) 585-593.

[15] T. Srisook, T. Vongsetskul, J. Sucharitakul, P. Chaiyen, P. Tangboriboonrat, Immobilization of 3-hydroxybenzoate 6-hydroxylase onto functionalized electrospun polycaprolactone ultrafine fibers: a novel heterogeneous catalyst, React. Funct. Polym. 82 (2014) 41-46.

[16] H. Ahn, B.C. Kim, S. Jun, M.S. Chang, D. Lopez-Ferrer, R.D. Smith, M.B. Gu, S. Lee, B.S. Kim, J. Kim, Robust trypsin coating on electrospun polymer nanofibers in rigorous conditions and its uses for protein digestion, Biotechnol. Bioeng. 107 (2010) 917-923.

[17] Z. Xie, G. Buschle-Diller, Electrospun poly(D,L-lactide) fibers for drug delivery: the influence of cosolvent and the mechanism of drug release, J. Appl. Polym. Sci. 115 (2010) 1-8.

[18] S. Sahoo, L.T. Ang, J.C. Goh, S. Toh, Growth factor delivery through electrospun nanofibers in scaffolds for tissue engineering applications, J. Biomed. Mater. Res. A 93A (2010) 1539-1550.

[19] J.S. Choi, S.H. Choi, H.S. Yoo, Coaxial electrospun nanofibers for treatment of diabetic ulcers with binary release of multiple growth factors, J. Mater. Chem. 21 (2011) 5258-5267.

[20] B. Krajewska, Application of chitin- and chitosan-based materials for enzyme immobilizations: a review, Enzym. Microb. Technol. 35 (2004) 126-139.

[21] F. Ding, H. Deng, Y. Du, X. Shi, Q. Wang, Emerging chitin and chitosan nanofibrous materials for biomedical applications, Nanoscale 6 (2014) 9477-9493. 
[22] S. Kubinova, E. Sykova, Nanotechnologies in regenerative medicine, Minim. Invasive Ther. Allied Technol. 19 (2010) 144-156.

[23] K.A. Rieger, N.P. Birch, J.D. Schiffman, Designing electrospun nanofiber mats to promote wound healing - a review, J. Mater. Chem. B 1 (2013) 4531-4541.

[24] S.M. McCarty, C.A. Cochrane, P.D. Clegg, S.L. Percival, The role of endogenous and exogenous enzymes in chronic wounds: a focus on the implications of aberrant levels of both host and bacterial proteases in wound healing, Wound Repair Regen. 20 (2012) 125-136

[25] S.K. McCallon, C. Frilot, A retrospective study of the effects of Clostridial collagenase ointment and negative pressure wound therapy for the treatment of chronic pressure ulcers, Wounds 27 (2015) 44-53.

[26] J. Connell, L. Rousselot, The use of enzymatic agents in the debridement of burn and wound sloughs, Surgery 30 (1951) 43-55.

[27] J. Ramundo, M. Gray, Enzymatic wound debridement, J. Wound Ostomy Continence Nurs. 35 (2008) 273-280

[28] J.D. Miller, E. Carter, D.C. Hatch, M. Zhubrak, N.A. Giovinco, D.G. Armstrong, Use of collagenase ointment in conjunction with negative pressure wound therapy in the care of diabetic wounds: a case series of six patients, Diabet. Foot Ankle 6 (2014), http://dx.doi.org/10.3402/dfa.v6.24999.

[29] J. Ramundo, M. Gray, Collagenase for enzymatic debridement a systematic review, J. Wound Ostomy Continence Nurs. 36 (2009) S4-S11.

[30] O. Jirsak, F. Sanetrnik, D. Lukas, K. Kotek, L. Martinova, J. Chaloupek, U.S. patent No. WO205024101 (2005).

[31] M. Slovakova, M. Sedlak, B. Krizkova, R. Kupcik, R. Bulanek, L. Korecka, C. Drasar, Z. Bilkova, Application of trypsin $\mathrm{Fe}_{3} \mathrm{O}_{4} @ \mathrm{SiO}_{2}$ core/shell nanoparticles for protein digestion, Process Biochem. 50 (2015) 2088-2098.
[32] P. Ye, Z. Xu, J. Wu, C. Innocent, P. Seta, Nanofibrous membranes containing reactive groups: electrospinning from poly(acrylonitrile-co-maleic acid) for lipase immobilization, Macromolecules 39 (2006) 1041-1045.

[33] S. Agarwal, J.H. Wendorff, A. Greiner, Chemistry on electrospun polymeric nanofibers: merely routine chemistry or a real challenge? Macromol. Rapid Commun. 31 (2010) 1317-1331.

[34] B.M. Brena, F. Batista-Viera, Immobilization of Enzymes, in: J.M. Guisán (Ed.), Immobilization of Enzymes and Cells 2006, pp. 15-30.

[35] A. Sassolas, L.J. Blum, B.D. Leca-Bouvier, Immobilization strategies to develop enzymatic biosensors, Biotechnol. Adv. 30 (2012) 489-511.

[36] K. Lee, C. Ki, D. Baek, G. Kang, D. Ihm, Y. Park, Application of electrospun silk fibroin nanofibers as an immobilization support of enzyme, Fibers Polym. 6 (2005) $181-185$.

[37] P. Ye, Z. Xu, J. Wu, C. Innocent, P. Seta, Nanofibrous poly(acrylonitrile-co-maleic acid) membranes functionalized with gelatin and chitosan for lipase immobilization, Biomaterials 27 (2006) 4169-4176.

[38] X. Huang, A. Yu, J. Jiang, C. Pan, J. Qian, Z. Xu, Surface modification of nanofibrous poly(acrylonitrile-co-acrylic acid) membrane with biomacromolecules for lipase immobilization, J. Mol. Catal. B Enzym. 57 (2009) 250-256.

[39] G.T. Hermanson, Bioconjugate Techniques, second ed. Academic Press, Amsterdam, 2008.

[40] G.T. Hermanson, Chapter 4 - Zero-length Crosslinkers, in: G.T. Hermanson (Ed.) Bioconjugate Techniques, third ed.Academic Press, Boston 2013, pp. 259-273.

[41] Y. Li, J. Quan, C. Branford-White, G.R. Williams, J. Wu, L. Zhu, Electrospun polyacrylonitrile-glycopolymer nanofibrous membranes for enzyme immobilization, J. Mol. Catal. B Enzym. 76 (2012) 15-22. 